\title{
HÁbITOS E PRÁTICAS ALIMENTARES NA SOCIEDADE PORTUGUESA Mudanças e reconfigurações
}

\section{HABITS AND EATING PRACTICES IN THE PORTUGUESE SOCIETY Reconfigurations and changes}

\author{
Luís Carlos S. Branco \\ Universidade de Aveiro, Departamento de Línguas e Culturas, Centro de Línguas, Literaturas e Culturas. \\ Campus Universitário de Santiago, 3810-193 Aveiro, Portugal. \\ E-mail: lcrsb@campus.ua.pt | ORCID: https://orcid.org/0000-0002-0726-6560
}

\begin{abstract}
Resumo: Este artigo dará conta, de modo panorâmico, das dinâmicas e reconfigurações dos hábitos e práticas alimentares dos portugueses, procurando assinalar os contrastes mais significativos entre o Estado Novo e as décadas seguintes, até à contemporaneidade. Para isso, utilizaram-se estudos de índole diversa, integrando-os e unificando-os. Fez-se uma seleção e revisão de literatura, analisando-se e confrontando-se, no texto, os seguintes tópicos: a institucionalização da segurança alimentar, a masculinização do espaço culinário, a alimentação como metáfora identitária e reificação de estatuto social, a gastronomia memorialística, o crescimento da cozinha de origem étnica, entre outros. Em resumo, podemos concluir que houve mudanças muito positivas se compararmos as práticas e hábitos alimentares durante a vigência da ditadura do Estado Novo (1933-1974), onde a pobreza e a falta de alimentos eram problemas preocupantes, com a abundância e variedade do Regime Democrático (1975-2021). Estas mudanças sinalizam também as grandes reconfigurações sociais, entretanto, ocorridas. Porém, existem agora problemas muito sérios, como, por exemplo, o distanciamento do padrão alimentar tradicional português, referente à saudável Dieta Mediterrânica, entre outros.
\end{abstract}

Palavras-chave: hábitos e práticas alimentares, sociedade portuguesa, Estado Novo, contemporaneidade.

\begin{abstract}
This article gives a panoramic account of the dynamics and changes in the habits and eating practices of the Portuguese society, pointing out the most significant contrasts between the Estado Novo and the following decades, particularly the contemporaneity age. A selection and review of literature was carried out to analyze and confront the following topics: the institutionalization of food security, the masculinization of the culinary space, food as an identity metaphor and reification of social status, memorialistic gastronomy, the growth of cuisine of ethnic origin, among others. In sum, we can conclude that there have been major positive changes if we compare the eating practices and habits in the dictatorship of Estado Novo (1933-1974), where poverty and lack of food was one of the main problems, with the abundance of the Democratic Regimen (1975-2021). These changes signalize also the great social transformations occurred in this country. Nevertheless, there are now very concerning problems, like, for instance, the divergence from the traditional and healthy Mediterranean diet pattern, among others.
\end{abstract}

Keywords: food and eating practices, portuguese society, Estado Novo, contemporaneity. 


\section{Introdução}

Repare-se na correlação entre o organismo humano individual e a sociedade em que está inserido e de como esse lugar, o corpo, é um espaço de inscrição social:

O homem está predestinado, ao nível biológico, a construir e habitar um mundo com os outros. Este mundo torna-se para ele a realidade dominante e definitiva. Os seus limites são estabelecidos pela natureza, mas, uma vez construído, este mundo reage sobre a natureza. Na dialética entre a natureza e o mundo social construído, o próprio organismo é transformado. Nessa mesma dialética o homem produz realidade e assim se produz a si mesmo. (Berger \& Luckmann, 1996/2010, p. 188)

Um dos objetos de estudo onde essa dialética poderá melhor ser apreendida, pois sinaliza, de modo inequívoco, essa correlação entre o orgânico e social é, sem dúvida, a alimentação. Nesse sentido, este artigo entende o fenómeno alimentar como total. Como é evidente, tal tipo de análise implica interdisciplinaridade e cruzamento de tópicos e resultados. Ou seja, ele só poderá ser entendido se, de facto, se tiver em consideração uma série de outros fatores sociais correlatos à alimentação, como é, por exemplo, o caso da alteração dos hábitos de consumo e compras, no qual são contempladas, por exemplo, as mercearias antigas e as recentes digitalidades alimentares.

Por outro lado, será difícil analisar convenientemente a temática alimentar sem se ter em consideração o quanto ela está implicada no topos da identidade nacional e da cultura. José Mattoso entrelaça o papel da História ao da constituição da memória coletiva, como um dos fundamentos da identidade nacional: "a História constitui para a sociedade atual um dos fundamentos mais importantes da memória coletiva, e, por conseguinte, da consciência de identidade" (Mattoso, 2008, p. 103). Ora, nesse sentido, a transformação das práticas alimentares está intrinsecamente relacionada com a questão identitária e, muitas vezes, funciona como reificação dela. Em concomitância, tenhamos também em consideração o que Pierre Bourdieu afirma e que poderemos transpor para os topoi alimentares:

O poder simbólico é um poder de construção da realidade que tende a estabelecer uma ordem gnosiológica: o sentido imediato do mundo (e, em particular, do mundo social) (...) Os símbolos são os instrumentos, por excelência da "integração social" enquanto instrumentos de conhecimento e comunicação, eles tornam possível o consensus acerca do sentido do mundo social. (Bourdieu, 1989/2011, p. 6)

Neste contexto, os alimentos são, assim, culturalmente densos e carregados de sentidos, são simbolicamente férteis, o que, para uma análise lúcida, impele a uma 
intersecção entre metodologias afetas à Sociologia (análise dataística, por exemplo) e os Estudos Culturais (as premissas do Materialismo Cultural) no sentido de apreender a totalidade desse fenómeno.

Com base nessas premissas, privilegiou-se o cruzamento de dados de tópicos correlacionados com a alimentação, em paralelo com outras mudanças sociais ocorridas (mudanças de teor económico, como o emergir da classe média, ou culturais, como a revalorização do masculino na sua relação com a cozinha). Optou-se também pela análise no tempo longo, pois, crê-se que, deste modo, são mais nítidas as dinâmicas sociais e mais visíveis as mudanças ocorridas. $\mathrm{O}$ tempo que permeia entre o Estado Novo e a contemporaneidade consubstancia o recorte temporal selecionado, pois, deste modo, será possível olhar analiticamente, de modo global e total, para o fenómeno alimentar na sociedade portuguesa e daí retirar conclusões pertinentes.

Nesse sentido, a metodologia utilizada diz respeito, sobretudo, à intersecção de bibliografia selecionada, análise documental e dataística. Assim, cruzando e relacionado documentos, dados e bibliografia, usualmente não analisada em conjunto, será possível obter um retrato da complexificação das mudanças alimentares na sociedade portuguesa, ao longo do tempo recortado, bem como problematizar as questões sobre as quais ela, hoje, se depara nesse âmbito.

Em suma, em vez de um artigo parcelar sobre um determinado tópico, ou subtópico, do fenómeno alimentar, optou-se, desde o início, por um trabalho que analise e dê a ver globalmente esse fenómeno. Tanto quanto se pôde apurar não existem muitos trabalhos com esta matriz totalizante e panorâmica sobre as práticas alimentares portuguesas, pelo que este trabalho poderá acrescentar uma visão própria ao estado da arte já existente e responder a algumas questões prementes sobre o fenómeno alimentar, entre elas, de que modo a alimentação interage, influencia e é influenciada, por outros fatores, como por exemplo, mudanças socioculturais e transformação das mentalidades.

Vejamos melhor alguns destas questões nos pontos seguintes.

\section{As materialidades da alimentação e o seu significado}

De algum modo, a alimentação sinaliza a sociedade e o regime político no qual se insere, por isso, este item enfocará as chamadas materialidades da alimentação. $\mathrm{Ou}$ seja, os modos efetivos e concretos por meio dos quais se consubstanciam as práticas alimentares.

A esse nível, a Revolução de 25 de Abril de 1974, e, depois, a inserção de Portugal no seio da Comunidade Económica Europeia (CEE), em 1986, representam dois 
momentos de transformação na sociedade portuguesa e, por inerência, no modo como os portugueses se alimentam. São dois marcos históricos, sociais e identitários ${ }^{1}$. A configuração da sociedade no pré e no pós 25 de Abril e antes e depois da entrada na CEE não é certamente a mesma e as mudanças na alimentação são dos primeiros campos socioculturais a dar sinal inequívoco disso. Atente-se que:

Alimentarmo-nos é um ato de cultura. O consumo de alimentos, necessário por razões biológicas, está repleto de significados, de imagens relacionadas com usos, situações e comportamentos coletivamente imaginados que constituem a alimentação em verdadeiro sistema de comunicação codificado de acordo com uma lógica simbólica. Através dessa lógica e através da alimentação, os grupos humanos comunicam a partilha de uma identidade interpretativa da existência. (Silva et al., 2002, p. 1)

Além destes dois momentos marcantes, também a crescente globalização, e a inserção de Portugal nesse movimento, e a explosão do digital, iniciada nos finais do século passado, mas com efetiva instauração no século XXI, são outros aspetos marcantes com profunda influência nos hábitos alimentares dos portugueses. Repare-se que:

Nos últimos cinquenta anos, no Ocidente, a produção industrial, a conservação, o comércio e os transportes influenciaram diretamente a alimentação e a culinária que num relativamente pequeno período de tempo passaram a aprovisionar-se em alimentos estandardizados, parcial ou completamente preparados para o consumo e, em grande parte, derivados de meios sintéticos. A industrialização aumentou a produção alimentar e provocou um incremento dos espaços e momentos em que se come, transformando as sociedades ocidentais em sociedades da abundância. (Silva et al., 2002, p. 1)

Assim, usando uma perspetiva advinda, em parte, do Materialismo Cultural, alicerçada nos recursos da Sociologia e da História Contemporânea, pretendo dar, assim, conta, nos pontos seguintes, da reconfiguração das práticas alimentares dos portugueses, desde o Estado Novo até à contemporaneidade.

António Barreto faz, assim, o balanço da evolução de Portugal em comparação com os seus parceiros europeus: "O sentido geral da evolução demográfica portuguesa foi o de uma aproximação dos padrões europeus conhecidos: envelhecimento, quebra de natalidade, alongamento da esperança de vida, redução da fecundidade, diminuição das dimensões dos agregados familiares, aumento das uniões de facto e dos filhos fora do casamento, acréscimo das famílias monoparentais, crescimento do número de divórcios, etc. O que sobressai no caso português é o facto de todos estes acontecimentos demográficos se terem iniciado, de certo modo, mais tardiamente do que no resto da Europa. Em consequência, foram muito mais rápidas, tendo, em muitos casos, ultrapassado as médias europeias (quebra de natalidade, redução do índice de fecundidade e ritmo de envelhecimento)." (Barreto, 2017, p. 50) 


\section{A institucionalização da segurança alimentar}

Ao nível da segurança alimentar, podemos assinalar uma notória melhoria desde o tempo da ditadura até aos nossos dias. Várias inflexões foram marcando esse melhoramento, o que nos permite, hoje, ter um assinalável grau de confiança nos produtos que adquirimos e que ingerimos.

Dois meses antes da Revolução dos Cravos, em fevereiro de 1974, foi criada a DECO (Associação Portuguesa para a Defesa do Consumidor), que, ainda hoje, é uma instituição fundamental para o controle sanitário, a qual os cidadãos podem recorrer, sem custos adicionais. Embora não seja uma agência de controlo alimentar, desempenha um papel de vigilância e alerta assaz importante, no qual os cidadãos parecem confiar e ao qual recorrem amiúde.

Mais tarde, com especial incidência no início do século XXI, foi dado um enorme passo no sentido de instaurar regras de higiene de segurança alimentar na circulação de bens e produtos, nomeadamente no setor retalhista e na restauração. Assim, e, de algum modo, na sequência dos escândalos da BSE (Bovine Spongiform Encephalopathy; Encefalopatia Espongiforme Bovina), uma doença que afetou os bovinos, designada também por Doença das Vacas Loucas, que teve consequências devastadoras no mercado global de venda de carne, no final dos anos 80 e meados dos anos 90, foi sendo preparado o terreno para a criação daquela que é, hoje, a entidade mais importante, em Portugal, ao nível da segurança alimentar: a ASAE (Autoridade de Segurança Alimentar e Económica), que foi criada em 2005.

Esta instituição faz visitas de inspeção frequentes a mercados, de tipologia variada, e a restaurantes e cafés, verificando se cumprem as normas de segurança alimentar legalmente instituídas. Nos primeiros anos, a sua ação foi muito pedagógica e eficaz na criação de uma verdadeira responsabilização dos empresários do setor alimentar. Nessa altura, vários estabelecimentos foram encerrados. Numa ação propedêutica, muitas destas visitas foram televisionadas, o que ajudou a passar a mensagem de intolerância das autoridades ante o incumprimento das regras de segurança alimentar. Com estas ações continuadas, é expectável que os cidadãos tenham passado a sentir-se mais confortáveis ao adquirirem produtos alimentares ou a irem alimentar-se fora de casa. Este papel, e fama de implacabilidade e rigor, dos inspetores da ASAE mantem-se, grosso modo, até aos dias de hoje.

Devido ao clima que se instaurou e a várias campanhas que se fizeram, também as pessoas, no seu dia a dia, estão mais alertas para a questão da segurança alimentar. A lavagem dos alimentos, sobretudo os crucíferos, e outras medidas correlacionadas, estão hoje relativamente bem difundidas. Porém, como é evidente, há muitos restaurantes e produtores que ainda não respeitam as tais regras. E os 
cidadãos, amiúde, não lavam devidamente as mãos, antes de manipularem alguns alimentos problemáticos, como a carne de frango, aumentando, deste modo, o risco de contaminação bacteriana (Didier et al., 2021).

Porém, no cômputo geral, há uma maior regulação e inspeção das regras sanitárias. Em todas as casas de restauração existe também um livro de reclamações, no qual qualquer pessoa pode reportar alguma anomalia alimentar que tenha encontrado e o dono do estabelecimento é obrigado a reportar às autoridades essas queixas ${ }^{2}$.

\section{Das mercearias de bairro aos clusters centros comerciais-hpermercados: a aquisição dos alimentos}

Em relação a este tema, convém, talvez, começar pelos seguintes dados. Segundo o INE (Instituto Nacional de Estatística), as despesas com a alimentação - com a exceção do período da Troika - , têm vindo a decrescer paulatinamente desde 1967. Por volta de 2010/11 estas despesas representavam cerca de $13 \%$ no orçamento familiar mensal dos portugueses, o que contrasta com os quase cerca de $50 \%$ registados em 1967/68. Portanto, os gastos com a alimentação perderam, na sociedade, a centralidade que outrora tinham, o que não é um dado de somenos. Os portugueses passaram a ter preocupações com outros gastos, que, na década de 60 e 70 não tinham. Hoje, as despesas com a educação, o lazer, a roupa e com a saúde são, em média, muito maiores (Rosa \& Chitas, 2010, pp. 93-100). A par disso, o mercado do retalho alimentar - os sítios onde os portugueses adquirem os alimentos - sofreu igualmente viragens assinaláveis.

Durante o regime salazarista a dieta portuguesa era, principalmente, constituída, por verduras e produtos hortícolas:

A cultura alimentar até à primeira metade do século XX em Portugal é de base vegetal, ou seja, é eminentemente vegetariana, por obrigação, como é, de resto, a grande cultura alimentar do Sul da Europa. A lógica é a de aproveitar tudo o que a horta pode dar, variando em função da estação do ano, da presença ou ausência de água, da qualidade da terra e da dimensão do espaço a cultivar. Tudo se come, tudo se mistura, tudo se coze. Os diferentes hortícolas misturam-se com outros vegetais ao longo do dia. Com cereais, com leguminosas e com tubérculos. Os hortícolas comem-se quase sempre cozinhados e raramente crus. Apesar da abundância de vegetais frescos, as saladas

2 Informações adicionais podem ser encontradas em: https://ahresp.com/2018/12/livro-de- reclamacoes/. E também em: https://www.asae.gov.pt/reclamacoes/livro-de-reclamacoes-emestabelecimentos-de-restauracao-e-de-bebidas.aspx. 
cruas são raras entre nós. É a grande tradição da comida de panela portuguesa, mistura de sabores genial que preserva os nutrientes e onde a diversidade e a criatividade estão presentes a cada momento. (Graça, 2020, p. 12)

Assim, até ao final da década de 60, os principais locais onde os portugueses se abasteciam eram os mercados, as mercearias, talhos, frutarias, padarias ou as, então em voga e hoje extintas, leitarias. Estas pequenas lojas, na sua maioria mono-alimentares (disponibilizando apenas uma categoria de produtos) cultivavam uma relação de proximidade com os clientes (fregueses). Estes, na sua maioria, moravam perto e, por isso, era-lhes permitido, por exemplo, levarem produtos sem pagarem de imediato (o chamado "fiado"), aguardando o recebimento do seu salário para reporem o dinheiro em falta. Além disso, havia um atendimento personalizado ao balcão; as compras eram mediadas. A pessoa pedia, e davam-lhe o que queria. Não existia self-service.

Com a entrada, no país, dos primeiros supermercados, esse panorama alterou-se completamente. Passou a vigorar o serviço livre. Ou seja, agora, são os próprios clientes que retiram os produtos que pretendem das prateleiras, a seu bel prazer, sendo obrigatório, depois, o respetivo pagamento à saída, nas caixas. Por um lado, o atendimento personalizado e de proximidade, acabou, mas a variedade de oferta e a liberdade de escolha, aparentemente, aumentou substancialmente.

Historicamente, o primeiro supermercado a surgir, com estas caraterísticas de autoabastecimento, em Portugal, foi o Supermercado Saldanha, em Lisboa, em 1961. Em sequência, já no pós-revolução, na década de 70, instalou-se a primeira rede de supermercados no país, que, durante muitos anos, marcou a paisagem urbana portuguesa e alterou comportamentos. Refiro-me à cadeia do Pão de Açúcar, de origem brasileira, criada por um emigrante português, Valentim Diniz, e, mais tarde, em 1987, comprada pelo Grupo Jerónimo Martins (após isso, mudou novamente de mãos, em 1996, para o grupo francês Auchan, e passou, a partir daí, a chamar-se Hipermercados Jumbo). Por sua vez, nos anos 80, surgiu aquela que é, atualmente, uma das mais importantes cadeias de hipermercados: a Modelo-Continente, pertencente ao Grupo Sonae, na altura, liderada pelo empreendedor Belmiro de Azevedo. Recorde-se que antes disso, eram usuais as idas a Espanha, por parte dos portugueses, para acederem aos centros comerciais, como ao El Corte Inglés, de onde traziam, por exemplo, roupas, caramelos e chocolates, de marcas inexistentes cá.

A entrada na CEE e a globalização alavancaram o processo de expansão e multiplicação destas cadeias de hipermercados. Para além do já mencionado Continente, apareceram também o já mencionado Jumbo e o Intermarché. Atualmente, estas redes de hipermercados cobrem praticamente todo o território e estão presentes nas principais cidades portuguesas e em todos os distritos. Proporcionam uma 
oferta vasta e competem ferozmente entre si. Com o intuito de fidelizar os clientes criam uma série de iniciativas atrativas: os cartões de clientes, os dias de descontos, a oferta de produtos na compra de outros, etc.

Entretanto, desde os idos anos 80, este modelo de venda retalhista sofreu várias alterações, refletoras das mudanças sociais. Não nos podemos esquecer que:

Sendo uma atividade de distinção e exclusão, a prática das compras serve para demarcar e classificar gostos, estatutos sociais, para veicular significados que são veiculados no espaço público, revelando a posição económica, social, cultural, ética e moral dos indivíduos ou grupos. Ir às compras é um indicador de gostos e preferências. (Truninger, 2018, p.34)

Surgiram, então, a partir dos anos 90 e com forte implantação, cadeias de média e pequena dimensão, como o Lidl, o Aldi e o Minipreço, que, de certa maneira, tentam emular as antigas mercearias, procurando ir ao encontro das preferências dos consumidores mais idosos - como os reformados. Têm uma oferta de produtos menos vasta do que a das grandes cadeias, mas muito mais de acordo com o gosto e com as limitadas possibilidades económicas de uma parte significativa dos seus clientes. Por outro lado, apareceram também alguns hipermercados dirigidos a uma classe alta, com grande poder económico, como é o caso do El Corte Inglés. Já em 2018, no contexto de um mercado cada vez mais global, o Mercadona, uma rede espanhola, também se instalou em Portugal. Assistimos, portanto, no século XXI, mas com origem nos anos 90, a uma cada vez maior segmentação do mercado.

Os grandes hipermercados, no sentido de captação dos clientes, operaram, nas duas últimas décadas, três grandes mudanças.

A primeira foi o terem alargado o seu tempo de abertura, prolongando-o durante a noite, o que permitiu a muitos clientes fazerem compras no final do dia, após saírem dos seus empregos. A segunda foi o passarem a ter gasolineiras no espaço dos seus recintos ou nas suas imediações. A última foi o facto de juntaram as suas instalações a centros comerciais. Assim, é usual encontrar no mesmo edifício supermercados e centros comerciais contíguos. A intenção subjacente a esta junção é a de que a clientela se abasteça dos bens de primeira e segunda necessidade nos supermercados e depois se encaminhe para o centro comercial para comprar outros produtos: roupas, sapatos, telemóveis, farmácias, etc. E, depois disso, se alimente no espaço das praças alimentares dos centros comerciais e, por fim, à saída encha o depósito do seu automóvel de gasolina nas bombas pertencentes aos hipermercados. Há quem, com alguma razão, chame a esta junção compósita de serviços e espaços: catedrais de consumo. 
Seja como for, houve alterações substanciais no modo como os portugueses acedem aos alimentos. Nesses hipermercados, os portugueses abastecem-se, em modo self service, dos bens essenciais e não só. Aumentou, sem dúvida, a variedade e a paleta de escolhas, mas também terá decrescido alguma qualidade. Há muitos produtos alimentares que são pré-cozinhados ou que são congelados e quase todos têm conservantes químicos. Os produtos frescos tornaram-se menos procurados e os bens derivados da agricultura biológica não são os mais consumidos pela maioria portugueses.

Outra prática que mudou foi a frequência com que os portugueses vão às compras de bens essenciais. Ao contrário do que sucedia nos anos 50, 60 e até 70, em que quase diariamente se compravam alimentos, hoje, é, geralmente, no final do mês, apôs receberem os seus salários, que as famílias se abastecem.

\section{O reavivar do comércio tradicional e da agricultura biológica}

Com a propagação dessas grandes unidades hipermercadistas, e das facilidades e variedade de serviços por elas disponibilizadas, o comércio de cariz tradicional teve uma queda abrupta e acentuada, entre os anos 80 e o novo século. Desde 1985 até 2009, viram-se obrigadas a fechar cerca de 24000 pequenas lojas, como mercearias e frutarias, o que teve um efeito trágico no setor. No entanto, nos anos mais recentes, este tipo de oferta tem vindo a ser revalorizada e tem surgido uma série de pequenas empresas de comércio tradicional bem-sucedidas.

Por um lado, tem havido um crescimento do mercado da saudade, com mercearias instaladas prioritariamente nos centros históricos das cidades, que se dirige, em primeira mão, aos turistas, mas também aos locais. Estas pequenas lojas optam por vender produtos de origem e marca portuguesas, com reminiscências e evocações do passado. Nelas, podemos encontrar sabonetes tradicionais, produtos enlatados, bolos sortidos, bolachas artesanais, mel e doces variados, vinhos portugueses, enchidos, etc ${ }^{3}$. Note-se, neste contexto o traço saudosista que, de algum modo, atravessa a

Todos estes produtos fazem parte das tradições alimentares portuguesas. Os produtos enlatados referem-se às sardinhas, lulas, e atum de conserva, cuja produção é bastante fomentada em Portugal, pois há uma indústria que se dedica ao seu comércio (por exemplo, junto ao porto de Aveiro). Por sua vez, os enchidos englobam uma série de alimentos, como os chouriços, morcelas, salpicão, as alheiras e as farinheiras, que têm em comum o facto de utilizarem carne, depois envolta numa tripa, que são cozinhadas em fumeiro, nas lareiras dos aldeões (daí o seu nome, pois "enche-se" essa tripa com carne e respetivos condimentos). Os enchidos fazem parte das tradições gastronómicas portuguesas, sobretudo, do Norte e Centro, como é o caso da famosa Alheira de Mirandela. Embora também usem carne de galinha, estão ligados à designada matança do porco, nas pequenas aldeias portuguesa do Norte montanhoso, principalmente nas regiões do Douro e Minho. Já os bolos sortidos são uma espécie de bolachas, de diferentes tamanhos, feitios e sabores, por vezes cobertas com chocolate, que são colocadas em pequenas latas, que as crianças apreciam particularmente e, antes da imensa variedade de doces hoje existentes, constituíam uma das principais guloseimas das crianças nos anos 70 e 80. Existem 
sociedade portuguesa e o mercado da saudade, de algum modo, sinaliza essa caraterística. A esse propósito, leia-se o retrato que Alfred Döblin (1940), médico e poeta alemão, fez do povo português":

O povo português é triste. (...) o termo saudade não é uma invenção de Coimbra (...) Os portugueses não têm a alegria dos homens do Sul; não se nota qualquer tipo de veemência, nenhum grito que advenha de uma emoção superlativa. Penso nos meus amigos, nos portugueses que conheci, na gente que vi nos comboios, nas praças da cidade, nos cafés, nos teatros. Embora não se possa dizer que são apáticos, aparentem uma estranha, inexplicável, morosidade que transparece em todos os seus movimentos: São melancólicos e sorriem de forma ausente: são afáveis, como todos os que consigo carregam um vago e inexplicável desgosto. (citado em Mónica, 2020a, pp. 266-267)

Por outro lado, tem-se assistido também a uma crescente tendência - ainda que não maioritária, ainda assim, assaz significativa, e em franca expansão - para que, ao invés de se comprar tudo no hipermercado, se opte por adquirir os produtos frescos, como fruta, peixe e carne, no comércio tradicional, em talhos e peixarias (Truninger, 2018, pp. 27-32), e, somente no final do mês, se vá, então, ao hipermercado comprar bens não perecíveis. Este tipo de lojas tem conhecido também um saudável retomar das suas atividades.

Neste contexto, devo sublinhar que Portugal foi considerado, durante muito tempo, o último país agrícola da Europa Ocidental. Porém, após a entrada na Comunidade Económica Europeia, essa ideia foi alterada. A instauração do PAC (Política Agrícola Comum), nos anos 80 teve como consequência imediata o início da desrruralização do país. Todavia, uma das medidas do PAC, a do Pilar III, foi fundamental para a criação do que é, hoje, um setor em franca expansão e que tem conhecido um grande incremento: o desenvolvimento de atividades rurais que tenham em consideração a preservação da natureza e os valores ecológicos.

Esta implantação continuou, nos anos seguintes, e o turismo rural a par da designada agricultura biológica teve um verdadeiro boom, bem patente, na segunda década do século XXI. Em consequência, também os hábitos de compra de um número significativo de portugueses se alterou.

várias fábricas portuguesas que se dedicam ao seu fabrico. As bolachas artesanais são feitas por pequenas empresas familiares e têm como caraterística não utilizarem produtos de conservação, nem quaisquer aditivos químicos, pelo que devem ser consumidas rapidamente, caso contrário deterioram-se.

4 Coetaneamente, o historiador José Mattoso corrobora a opinião do poeta alemão, quando, por exemplo, diz: "Apontar a permanência de estruturas de longa duração que parece poderiam relacionar-se com determinadas tendências mentais aparentemente muito comuns, como sejam, para dar apenas dois exemplos, a saudade associada ao lirismo e a reduzida capacidade de planeamento aliada à tendência para a improvisação." (Mattoso, 2008, p. 105) 
Assim, hoje, valoriza-se e compra-se muito mais produtos de origem biológica, cultivados em hortas de média dimensão, sem recurso aos químicos agrícolas. Ilustrativo desta evolução é o estudo do OBSERVA5 , em 2018, que regista mudanças relevantes nos hábitos e gostos de consumo alimentar dos portugueses. Atualmente, $49 \%$ dos inquiridos recorre ao comércio tradicional e às pequenas lojas de proximidade; $66 \%$ aos hipermercados/centros comerciais; e cerca de 39\% abastecem-se nas feiras e mercados tradicionais, que, entretanto, também conheceram uma revitalização.

\section{Tecnologia e alimentação ${ }^{6}$}

\section{A primeira revolução: os eletrodomésticos}

Também ao nível tecnológico houve um progresso notável desde o Estado Novo até à Contemporaneidade. Portugal passou a poder aceder à tecnologia que transformou radicalmente o seu modo de se relacionar com a comida. Atente-se aos impressionantes dados estatísticos:

Em 1951, apenas 8\% dos lares usavam grandes aparelhos elétricos - como máquinas de lavar roupa ou frigoríficos - número que aumentaria para 70\% em 1975. Avançando 12 anos para 1987, vemos que a percentagem de agregados familiares com frigoríficos era de $86 \%$, valor que subiu continuamente até chegar à quase totalidade, 99,3\%, em 2015. (Truninger, 2018, pp. 47-48)

A este propósito, deve-se salientar a sua correlação com as paupérrimas condições económicas que, grosso modo, caraterizavam o país. No tempo da ditadura salazarista, mais precisamente na década de 50, Mary MacCarthy (1954), escritora inglesa ligada ao Bloomsbury Group, onde pontificava Virgina Woolf, visitou Portugal e ficou chocada ante o panorama socioeconómico, para ela inesperado, com o qual se deparou:

Tive simultaneamente medo e repulsa diante daquela horrível pobreza. (...) É fácil a um estrangeiro de passagem por Lisboa ficar encantado pela fruta, pelas flores, pelas cascatas de bolos, pelos queijos e pelas salsichas em montras profusamente enfeitadas, não notando a pobreza existente ou então assimilando-a a um traço pitoresco. (...) A diferença entre os ricos e os pobres é, em Portugal, tão extrema que terá levado,

5 O OBSERVA é um observatório do Instituto de Ciências Sociais da Universidade de Lisboa que trata, disponibiliza e comunica informação científica sobre ambiente, território e sociedade em Portugal. O Observa tem como missão fortalecer a relação entre academia e sociedade civil. (Vd. https://observa.ics.ulisboa.pt/)

6 Para mais detalhes sobre este ponto e o ponto seguinte (A masculinização do espaço culinário) consultar: Truninger, 2018. 
no caso dos ricos, à formação de uma carapaça que os torna indiferentes a tudo o que os rodeia. (citado em Mónica, 2020a, pp. 301-305)

Após esta contextualização, comecemos a nossa explanação, neste ponto, por algo que hoje damos por adquirido, mas que, durante muito tempo, foi, em Portugal, uma verdadeira dificuldade: a conservação dos alimentos.

Durante a ditadura fascista, era inexistente uma cadeia do frio, que permitisse congelar os alimentos ou simplesmente mantê-los em bom estado de conservação algum tempo. Recorria-se, por isso, a métodos seculares herdados, como o sal grosso, a secagem ao sol e ao vento, o vinagre e a salmoura. Chegou-se, por essa altura, a criar uma Comissão Nacional do Frio, mas que, para além da instalação de alguns armazéns frigoríficos, em Lisboa e Porto, para o bacalhau, nada mais fez.

Só depois do 25 de Abril é que se instalou no país uma rede elétrica eficaz e abrangente, o que espoletou uma verdadeira revolução nas cozinhas dos portugueses. O uso de eletrodomésticos generalizou-se, a começar pelo, hoje indispensável, frigorífico.

Sublinhe-se que, por volta da década de 60, ele estava longe de ser um utensílio acessível e normalizado. Quer a falta de uma rede elétrica que cobrisse devidamente o território, quer a falta de recursos económicos, impediam que ele estivesse presente na maioria das cozinhas portuguesas. Era um bem de luxo destinado à burguesia endinheirada e escolarizada. Só nos anos 80 é que o frigorífico se tornou omnipresente nos lares portugueses, configurando, desse modo, uma verdadeira Rede Nacional do Frio. Isto transformou a forma como os portugueses se relacionavam com os alimentos. Passou a ser possível congelar bens essenciais, como carne e peixe, e prolongar, em boas condições, leite, ovos e fruta.

Logo após a disseminação do frigorífico seguiram-se outros eletrodomésticos, o que teve um grande impacto nos hábitos e nos rituais alimentares, entre os quais, a máquina de lavar louça e o micro-ondas. Devido a este último, generalizou-se o uso de comida pré-cozinhada. Em 1996, ele fazia parte de 11,6\% das cozinhas portuguesas. Em 2015, está já presente em 89,9\% (Truninger, 2018, pp. 47-48). Também a utilização do robô da $5^{\mathrm{a}}$ geração (a Bimby), sobretudo entre a classe média alta, se vulgarizou e muitas famílias portuguesas recorrem a ela no seu quotidiano alimentar (Truninger, 2018, pp. 57-62).

\section{A segunda revolução: as TIC e a digitalização da alimentação}

De modo indireto, também a normalização crescente das TIC (Tecnologias de Informação e Comunicação) nas casas portuguesa teve um assinalável impacto nas práticas alimentares. 
A televisão está presente em 98,9 \% dos lares, o uso do telemóvel generalizou-se e $66,6 \%$ das famílias possuem computadores em casa. As redes sociais têm também desempenhado um papel relevante na mudança de paradigmas alimentares. Muitas pessoas retiram receitas de lá e vulgarizou-se a postagem de fotografias de pratos confecionados. No Facebook e Instagram assistimos a um verdadeiro "desfile de moda" de comida, procurando constantemente chamar a nossa atenção. De lá também se têm propagado, de modo massivo, algumas modas alimentares, como a dieta paleo e o crudismo. De facto, há uma omnipresença da comida no espaço intermediático. Sobre esta questão, Paula Guerra e Kadma Marques fazem a seguinte síntese:

A comida nunca esteve tão presente nas nossas sociedades como hoje: são constantes estudos sobre qual melhor alimentação para curar toda e qualquer doença; as várias dietas e livros e blogues que as acompanham; o MasterChef Brasil e os seus derivados em que a gastronomia é o personagem principal; os vários canais dedicados $24 \mathrm{~h} / 7$ à gastronomia, como o Food Channel e o 24 Kitchen. Eve Turow cunhou inclusivamente o termo geração Yum para caracterizar os jovens americanos obcecados por comida e gastronomia. Belasco não se coíbe de analisar as profundas relações entre alimentação e sexualidade que encontramos hoje em dia. O que faz com que muitos cunhem o termo food porn. (Guerra \& Marques, 2018, p. 16)

Outra das mudanças, atualmente, em franca expansão, tem a ver com as encomendas de produtos on-line, e é modulada segundo dois vetores. O primeiro diz respeito à possibilidade de encomendar cabazes de produtos alimentares, por exemplo, nos hipermercados e plataformas de venda de produtos agrícolas, que os vêm trazer a casa - o que aconteceu amiúde durante o confinamento. O segundo tem a ver com a instalação, em território nacional, de empresas especializadas nos serviços de take-away, permitindo às pessoas encomendar refeições de modo célere e eficaz. Num estudo realizado pelo IMR (Instituto de Marketing Research) verificou-se que cerca de $48 \%$ dos sujeitos estudados tinham as aplicações destas empresas instaladas nos seus telemóveis, o que corrobora a força que está a ganhar esta tendência de digitalização da alimentação:

Há mais pessoas a utilizar aplicações de telemóvel para encomendarem comida, por exemplo, através de serviços como a Uber Eats ou a Glovo. (...) Esta tendência aumentou ainda mais durante a pandemia da Covid-19, quando os restaurantes foram obrigados a encerrar portas. A digitalização da alimentação é uma tendência que veio para ficar, notando-se que os telemóveis fazem cada vez mais a mediação tecnológica, tanto na compra dos alimentos como na reserva das refeições como ainda na preparação de refeições em casa (por exemplo, procura de ideias de receitas quando se vai cozinhar). (Truninger 2018, pp. 37-38) 


\section{A masculinização do espaço culinário}

Outra transformação a que temos vindo a assistir no novo século, sobretudo, na segunda década, configura-se como masculinização do espaço da cozinha - o que seria algo completamente impensável de suceder no Estado Novo ou mesmo alguns anos após o 25 de Abril.

Atualmente, são muitos os homens que colaboram nas tarefas da cozinha, quer cozinhando, quer em tarefas adjacentes, como lavar loiça, preparar alguns alimentos, etc. O número dos que se dedicam a estas tarefas tem aumentado, sobretudo, em pessoas abaixo da faixa etária dos 45 anos. No entanto, sublinhe-se, continua a caber à mulher, numa percentagem esmagadora, a desgastante tarefa de assegurar as refeições diárias das famílias. Somente 22,8 \% dos homens tem este encargo sobre os seus ombros.

Em correlação com isso, mas a outro nível, muito por influência de novos programas televisivos, os quais podemos categorizar como Kitchen Realitty Shows, caso dos vários Masterchefe do Pesadelo na Cozinha, a figura do cozinheiro, que era vista, durante a ditadura e nas primeiras décadas do pós 25 de Abril, como alguém pouco instruído, com baixo estatuto social e pouco interesse intelectual, alterou-se substancialmente.

Para esta mudança de estatuto terá contribuído também o franco desenvolvimento da indústria hoteleira e a atribuição das prestigiadas Estrelas Michelin, que premeiam os melhores cozinheiros do mundo, a restaurantes portugueses, que, assim, passaram a fazer parte desse importante roteiro internacional.

Tem havido uma exposição mediática, mormente na televisão, de alguns chefes de cozinha, que, desse modo, passaram a fazer parte do star system português. É o caso de, entre outros, Ljubomir Stanisic, José Avilez e Henrique Sá Fernandes. Com uma culinária sofisticada, em grande parte inspirada pela cozinha e pelos alimentos tradicionais portugueses, eles têm ajudado a restaurar o estatuto do cozinheiro, sendo, hoje, proeminentes figuras no espaço das TIC. Muitos jovens querem seguir as suas pegadas e aderir a essa profissão tornou-se, agora, bastante atrativo. O salto qualitativo, dado nos últimos anos, na formação em hotelaria e culinária também terá tido, neste caso, um papel importante.

Em termos de consumo, apesar de ser dispendioso, muitos portugueses, sobretudo nos grandes centros urbanos, como Lisboa e Porto, frequentam os restaurantes destes cozinheiros vedetas. Repare-se que "os objetos culturais são produtos que suscitamo desejo dos indivíduos, hoje dispostos a pagar para terem acesso à cultura." (Dias \& Baptista, 2006, p. 43), e nós devemos sempre considerar, tal como se tem vindo a chamar a atenção ao longo deste artigo, que os alimentos são também bens culturais, carregados 
de simbolismo. Estes chefes, atentos a este aumento da procura, criaram, entretanto, sucursais e ramificações dos seus restaurantes principais com preços mais acessíveis e para públicos diversificados, mas mantendo o seu poder simbólico irradiante.

\title{
Gastronomia memorialística
}

Como sabemos, a alimentação está intrinsecamente ligada aos mecanismos rememorativos:

\begin{abstract}
As práticas alimentares revelam em que cultura o indivíduo está inserido. Uma das melhores formas de analisar esta questão é por meio da relação entre alimentação e memória. $\mathrm{O}$ ato de comer, especialmente a partir dos cheiros e sabores, desperta poderosas pistas mnemónicas que nos acompanham para toda a vida. É preciso recordar que o ato de comer conjuga as esferas públicas e privadas. Pode ser um ato privado, sim, mas na maioria das situações encontra-se integrado num conjunto de rituais de partilha, banquetes e trocas recíprocas ou, mais prosaicamente, em contextos de compra e venda de comida. Independente de um ou outro, trata-se de um fator explicativo para o poder simbólico da comida. (...) Os nossos hábitos alimentares são convenções que se foram transformando numa memória cultural. (Guerra \& Marques, 2018, p. 17)
\end{abstract}

Em correlação com essa ligação memorialística à comida, a cozinha de autor, referida no ponto anterior, tem-se dedicado a explorar esta vertente. Assim, uma das suas caraterísticas mais marcantes é o que designo por gastronomia memorialística.

Note-se que estes prestigiados chefes se inspiram em pratos tradicionais portugueses e se baseiam em produtos nacionais para afirmarem e consolidarem a sua arte culinária. Por exemplo, José Avilez recria: os saloios e típicos Peixinhos da Horta lisboetas, o polvo assado, as receitas à Bolhão Pato, os camarões algarvios (os carabineiros), etc 7 . Por sua vez, o chefe Rui Paula vai mais longe, pessoalizando esta questão, fazendo dos seus pratos uma espécie de livro de memórias. Aliás, ele intitula o seu menu de Cozinha de Memórias. Nele, podemos encontrar pratos como açorda de bacalhau, queijos e presuntos, polvo e inclui dois menus de degustação intitulados "Memória" e "Mar"8. Com isto, pretende-se que o ato de comer se torne uma experiência sensorial o mais completa possível, apelando aos mecanismos rememorativos do cliente. A este título, leia-se o seguinte excerto de um artigo de Paula Guerra e Kadma Marques:

$7 \quad$ Vd. José Avillez, https://www.joseavillez.pt

8 Vd. Rui Paula, https://www.ruipaula.pt/ 
E aqui chegamos aos conceitos de memória gustativa e alimento-memória. São ambos conceitos proustianos, isto é, que defendem que a comida ao ser degustada conduza a experiências sensoriais que transcendem o aqui e o agora. Daí a usual expressão isto faz-me lembrar a minha infância ou a comida da mãe e avó. Como já referimos, a comida é um meio de comunicação. Assim sendo, a memória gustativa e os e alimento-memória são memórias de comunicação que os indivíduos constroem todos os dias, mas que não podem apenas ser associadas à memória individual. Também dependem, e muito, da memória coletiva, de um conjunto de representações e práticas que herdamos e que carregamos para onde quer que vamos. (Guerra \& Marques, 2018, p. 18).

Contudo, esta tendência não se restringe à alta cozinha e assume, hoje, um caráter transversal. Veja-se, por exemplo, alguns restaurantes, como o 5uinhentos \& 5inco - Cozinha de Memória e outros, que atestam essa interligação e essa tendência. Sublinhe-se o seguinte:

Infelizmente, a questão da identidade nacional tem sido abordada de forma essencialista, ou seja, como se Portugal tivesse nascido ab initio com as suas caraterísticas. A única forma de lutarmos contra isto é através de um conhecimento profundo da História e da Geografia. (...) Em suma, não há uma "portugalidade" acima da História: não porque todas as nações sejam iguais, mas porque as culturas têm uma raiz material. A "alma portuguesa" só é explicável através dos fatores - políticos, económicos e culturais - que lhe estão na base. Não somos excecionais: somos diferentes porque diferentes foram os fatores que assim nos tornaram. (Mónica, 2020b, pp. 33-45)

Assim sendo, cada vez mais, a culinária se tem constituído como um importante elo de ligação histórico-social dos portugueses ao seu passado. Ao contrário de uma obra de arte ou uma peça arquitetónica da História Portuguesa, a comida é deglutida, tem um aspeto de incorporação muito vincado, o que a torna propensa a marcas identitárias e históricas. A isto também não será alheio o grande salto no turismo que tem sido dado nos últimos anos, onde, entre outras coisas, a gastronomia portuguesa passou a ser um ex libris por excelência da "marca" Portugal.

\section{O crescimento da cozinha de origem étnica e da alimentação fora de casa}

Em 2018, segundo dados do Eurostat, as famílias portuguesas gastaram, em média, $9,2 \%$ do orçamento mensal familiar em refeições fora de casa. Isto significa que os portugueses são o povo europeu que mais come fora de casa. No entanto, note-se, esta tendência começou no século XX: 
Este fenómeno da alimentação fora de casa, não constitui uma realidade recente. Até aos finais do século XVIII, comer e, sobretudo, beber no exterior era frequente para as categorias sociais de cariz popular. Na década de sessenta do século passado, emerge o turismo de massa. Os restaurantes, os hotéis, as casas de chá, os cafés multiplicam-se, coexistindo, porém, com as casas de pasto, tascas e tabernas frequentadas pelos grupos sociais de cariz popular. Nos meados dos anos setenta do século passado, começa-se a valorizar as sociabilidades nas tascas e nas casas de pasto como lugares de interesse pela cultura popular. No entanto, estes estabelecimentos são essencialmente espaços das classes populares, enquanto os cafés, bares e bares de luxo revelam-se como espaços das classes médias, médias-altas e altas. (Mascarenhas, 2012, pp. 16-17)

Atualmente, o panorama é este:

O gosto pela boa comida atravessa as diferenças sociais e é um grande denominador comum. (...) é instilado desde uma tenra idade. (...) Os portugueses são frequentemente capazes de fazer um longo desvio de carro para provarem um apreciado prato local. (...) Com um clima tão ameno, comer fora é possível durante grande parte do ano. A vida no exterior é uma faceta da cultura que ajuda a tornar os portugueses um povo tão convivial e sociável. (Hatton, 2011/2017, pp. 260-263)

Também o take away é outro hábito que se começa, agora, a enraizar e que o contexto pandémico acentuou. É usual para muitos portugueses, ao final de um dia, passarem no hipermercado para fazer uma ou outra compra e, depois, de lá levarem o jantar, normalmente comida rápida como pizzas ou frango de churrasco. O almoçar ou jantar fora, seja nas praças alimentares dos centros comerciais, seja numa churrascaria ou num restaurante gourmet, é uma prática generalizada na sociedade portuguesa.

Neste contexto, outra mudança importante a reter na paisagem alimentar portuguesa é o aumento exponencial da cozinha de origem étnica, inexistente em Portugal no pré 25 de Abril.

Após a descolonização, muitos africanos, originários das ex-colónias, emigraram para Lisboa e Porto, dando origem aos primeiros restaurantes de comida africana. Pratos como a Muamba ou a Cachupa passaram a fazer parte do vocabulário alimentar de uma classe média, culta e escolarizada, que ia, com regularidade, a esses estabelecimentos de restauração ${ }^{9}$.

Muamba de galinha é um prato típico da culinária angolana. Constitui um dos pratos mais populares do país. A sua confeção envolve, para além da galinha, amendoim, óleo de palma, quiabos, gindungo, cebola e alho. Cachupa é um prato típico da gastronomia de Cabo Verde. Para além da carne ou do peixe, a cachupa é elaborada com feijão e milho estufados, servidos, por vezes, separados dos legumes cozidos. Entre estes últimos podem juntar-se a batatas e banana cozidas. 
Em seguida, nos anos 80, com a progressiva instalação de bazares chineses nas nossas cidades, assistiu-se a uma proliferação de restaurantes oriundos dessa etnia. Também a cozinha de origem brasileira, com os seus caraterísticos grelhados, como é o caso da Picanha, com a forte vaga de emigração dos anos 90, se tornou mais visível e presente.

No novo século, esta tendência da cozinha de origem étnica expandiu-se rapidamente para todo o país. Com as novas ondas de emigrantes de proveniência diversa, outras cozinhas vieram ocupar um lugar de destaque na oferta alimentar, como é o caso notório da cozinha de proveniência japonesa. O sushi passou a fazer parte dos gostos e do consumo habitual de muitos portugueses. Veja-se a seguinte análise deste fenómeno, efetuada por Maria do Céu Antunes Martins:

\begin{abstract}
Em Portugal, no que se refere a práticas alimentares oriundas de outras países, verifica-se atualmente uma maior disponibilidade e diversidade. Durante muito tempo, as cozinhas de outros países constituíam qualquer coisa de exótico e de raro consumo. Neste momento as gastronomias internacionais intensificam-se, em grande parte à custa dos imigrantes, $\mathrm{e}$ com relativa facilidade os portugueses podem optar por consumir no seu país comida típica de outros países. Relativamente às novas matérias-primas que podem ser observadas (por via do fenómeno migratório) (...) não há dúvida, que a imigração constitui um elo importante da globalização/localização alimentar. As grandes correntes de imigrantes são determinantes no estabelecimento de alguns fluxos de matérias-primas, da crescente diversidade e disponibilidade de alimentos. São também responsáveis pela expansão de culturas gastronómicas, tanto através das comidas confecionadas em casa como em restaurantes, cujo uso acaba por se alargar a toda a população. (Martins, 2009, p. 3)
\end{abstract}

Acrescente-se que alguns dos pratos dessas culinárias foram também alvo de uma espécie de apropriação portuguesa. Foi o que sucedeu com a cozinha de origem italiana, com pizzas e massas a serem feitas por portugueses e a incorporarem alimentos nacionais, como a alheira e o presunto. O mesmo se passou com o sushi, feito com peixes caraterísticos da alimentação portuguesa, como o bacalhau.

\title{
A alimentação como metáfora identitária e reificação de estatuto social: o caso do bacalhau e de outros pratos tradicionais
}

Tal como um carro ou uma casa, os alimentos são símbolos de estatuto social. Atente-se no seguinte: "A cultura emerge e revela-se na forma como os povos se vivem e se representam a si próprios no momento em que produzem cultura" (Dias \& Baptista, 2006, p. 29). E sem dúvida que os alimentos e a culinária representam os povos e as regiões em que são confecionados; são cultura objetificada. A esse propósito, veja-se o 
significativo exemplo de um dos mais apreciados alimentos em Portugal: o bacalhau.

No século XVI e XVII, era um alimento de pobres. No período do Estado Novo, passou a ser um bem alimentar caro, ao qual só acediam as pessoas mais abastadas. Noutros moldes e com outros contornos, assistimos, hoje, em relação à sardinha, a um processo valorativo idêntico. Deixou de ser, nos últimos anos, um alimento barato e pouco apetecível para as classes mais altas, para passar a ser muito apreciado e com um preço relativamente elevado. Sinal desta mudança é o facto do seu consumo ter extravasado a época das Festas dos Santos Populares. Como é evidente, os alimentos contêm em si ineludíveis marcas identitárias:

A alimentação é mais do que uma necessidade biológica, já que o que comemos, quando, com quem, onde e porquê a colocam no centro de interesse político, social, cultural, económico, ambiental, gastronómico, de lazer e mediático. Os nossos hábitos alimentares norteiam identidades sociais e culturais, marcando a pertença a uma comunidade concreta e, como tal, expressando ao mesmo tempo demarcação várias de outros grupos. (Truninger, 2018, p. 7)

Daqui se depreende que os alimentos mais tradicionais, não só o bacalhau, mas também o azeite, os queijos e enchidos, os doces regionais, têm um inegável cunho identitário ${ }^{10}$. É o que designo por alimentação saudosa. Os emigrantes em férias, quando regressam à nação onde trabalham, fazem questão de os levar. É uma forma de se sentirem mais perto de Portugal. A saudade impregna os alimentos. Em termos identitários, comê-los equivale, metaforicamente, a deglutir a pátria e encurtar distâncias. Os sentimentos saudosos e a alimentação estão umbilicalmente ligadas. E, nesse enquadramento, não devemos perder de vista os seguintes aspetos, para os quais os sociólogos Peter Berger e Thomas Luckman nos chamam a atenção:

A sociedade penetra também no organismo, de maneira direta, no que diz respeito ao funcionamento deste, em especial quanto à sexualidade e à nutrição. Embora ambas sejam baseadas em impulsos biológicos, estes impulsos são muitíssimo plásticos no animal humano. O homem é levado pela constituição biológica a procurar satisfação

Sendo uma cozinha com fortes raízes mediterrânicas, é utlizado amiúde, na culinária portuguesa, como tempero e "molho" principal em muitos pratos, o azeite. As azeitonas também são consumidas, quer como acepipes, quer acompanhando as refeições principais. O azeite virgem, ou extra virgem, é muito apreciado pelos portugueses e considerado um produto alimentar de luxo. Os doces regionais, como os famosos ovos moles ou as barrigas de freiras, fazem parte dos ex libris gastronómicos portugueses. São feitos à bases de ovos, amêndoa, gila e farinha. Muitos destes doces são originários da doçaria conventual, ou seja, criada pelas freiras nos séculos passados. Portugal também tem uma arraigada tradição queijeira, com base no leite de vaca e cabra. São famosos, por exemplo, os amanteigados queijos da Serra da Estrela e os condimentados queijos do Alentejo, e são também produtos de exportação. 
sexual e alimento. Mas a sua constituição biológica não lhe diz onde poderá procurar a satisfação sexual e o que deverá comer. (...) Assim, funções biológicas tão intrínsecas quanto o orgasmo e a digestão são estruturados pelo social. (Berger \& Luckmann, 1996/2010, pp. 186-187)

Tendo em consideração o passado, é possível perceber que o processo de verticalização social de certos alimentos, é observável também na famosa Açorda Alentejana, que foi criada pelos desvalidos trabalhadores do campo alentejanos. Atualmente, é um prato caro, que foi alvo de mutações várias, como por exemplo, a Açorda de Marisco, num contraste nítido com as suas origens humildes.

Contudo, o exemplo mais paradigmático talvez seja o do vinho, que era enaltecido pelos avatares do Estado Novo, como altamente aconselhável para os operários e os agricultores, e cujo consumo, entretanto, se verticalizou, expandindo-se a toda a sociedade.

Aliás, nessa malograda época, o consumo de carne e peixe só era possível às classes mais abastadas, que constituíam uma minoria. $O$ povo alimentava-se à base de batata, pão, hortaliça, legumes, alguma carne de porco e sardinhas. Para além da falta de proteína animal, também o leite, o queijo e a fruta escasseavam entre a maioria da população. O povo alimentava-se mal e tinha acesso apenas a uma variedade de alimentos muito reduzida.

É célebre a frase de Oliveira Salazar, aquando do espoletar da 2. a Guerra Mundial: "Livro-vos da guerra, mas não vos livro da fome". Claro que, ao contrário do que o ditador queria fazer crer, as razões para a fome estavam a montante. Os cofres estatais, com o constante influxo monetário das colónias, estavam cheios. Na verdade, os mentores do Estado Novo sempre quiseram que o povo fosse não escolarizado, malnutrido e obediente. São inúmeros os sofridos relatos de pessoas que nos contam que era habitual uma sardinha ter de ser dividida por vários elementos da família, que, nessa altura, eram muito numerosas e paupérrimas, situação pela qual, sublinhe-se, nenhum dos líderes da União Nacional teve de passar.

\section{O decrescimento da Dieta Mediterrânica, a pobreza e o emergir de valores ecológicos}

Hoje em dia, a carne, que reificava o bem-estar social no Estado Novo, continua a ser um símbolo de estatuto social, mas, agora, em sentido inverso. Devido aos recentes avanços científicos, que demonstram os seus malefícios, o seu consumo desceu abruptamente entre as pessoas mais escolarizadas e abastadas. E, neste âmbito, não podemos esquecer que há ainda franjas da população portuguesa que subsistem 
com grandes dificuldades económicas. É bastante significativo o que, sobre isso, disse, em 2016, a socióloga Maria Filomena Mónica:

Depois de 1974, imaginei que a pobreza absoluta estava em vias de desaparecer, mas depressa verifiquei até que ponto estava enganada. (...) O estudo afirma que, em 2014, dois milhões de portugueses se encontravam em situação de pobreza, ou seja, mais 116 mil do que em 2009. (...) Existiria, além disso, um fosso geracional. Na sua opinião, os jovens teriam perdido $29 \%$ dos seus rendimentos. (...) Sim, há pobres em Portugal. (Mónica, 2020b, pp. 186-211)

Portanto, atualmente, entre as classes menos favorecidas, assistimos a um afastamento da tradicional Dieta Mediterrânica, em favor de um preocupante consumo de fast food (economicamente mais acessível) e de uma perniciosa ausência de legumes e frutas no seu regime diário, o que inevitavelmente causa danos na saúde pública. $O$ lugar de Portugal, em 2000, relativo ao consumo per capita de vegetais e frutos frescos nos países da União Europeia, ficava, já nessa altura, atrás dos outros países tradicionalmente afetos à Dieta Mediterrânica, como a Grécia e a Itália11. Aliás, em 2012, era já notória a diferença entre os anos 90 e a tendência no novo século:

A comparação da distribuição das disponibilidades diárias per capita da Balança Alimentar Portuguesa com o padrão alimentar preconizado pela Roda dos Alimentos continuou em 2012 a evidenciar distorções, apontando para excesso de produtos alimentares dos grupos "Carne, pescado e ovos" (com tendência acentuada para decréscimo), e "Óleos e Gorduras" e défice em "Hortícolas", "Frutos" e "Leguminosas secas". Este desequilíbrio continua a ser potencialmente pouco saudável, com uma predominância de proteínas de origem animal e excesso de gorduras. Estas disponibilidades alimentares traduzem para 2012 um índice de adesão à dieta mediterrânica1 de 1,10, sendo que um índice superior a 1 revela uma predominância de calorias provenientes de produtos típicos de uma dieta mediterrânica. Este índice, embora com tendência crescente desde 2006, situa-se, contudo, abaixo dos valores alcançados no início da década de 90. (INE, 2014, p. 1)

De fato, as principais causas de morte em Portugal continuam a dever-se a hábitos alimentares pouco salutares. Assim, as populações mais pobres são também as mais obesas, malnutridas e, em consequência, doentes:

Não é assim de estranhar que o acesso a produtos frescos, de qualidade, nutricionalmente equilibrados, provenientes de sistemas alimentares sustentáveis esteja facilitado

11 Consultar: http://www.alea.pt/index.php?option=com_content\&view=article\&id=458\&Itemid=1547\&lang $=p t$ 
em determinadas zonas - de estatuto económico, social e cultural elevado - e não noutras, onde as populações vivem com orçamentos apertados, são pouco escolarizadas e provêm, numa parte significativa dos casos, de minorias étnicas. Estas populações acabam por não ter acesso a uma alimentação nutricionalmente adequada, havendo muitas vezes, consequências para o seu estado de saúde. Vários estudos científicos têm comprovado a relação estreita entre pobreza, obesidade e estado de saúde das populações, por um lado, e a distribuição geográfica no território nacional destes fenómenos, por outro. (Truninger, 2018, p. 33)

Por sua vez, as classes mais elevadas tendem a aproximar-se dos ideais da Dieta Mediterrânica. Há um problema incontornável: quanto mais saudável a comida, mais cara se torna. Daí que, em grande medida, uma alimentação cuidada não é acessível ao português médio. Por exemplo, os preços da comida biológica são, para a maioria das famílias, proibitivos. Também o peixe, que se afigura uma alternativa mais saudável do que a carne, é caro e não permite um consumo regular à maioria dos agregados familiares. Ainda assim, muitas pessoas pertencentes a meios depauperados, principalmente as mais escolarizadas, tentam contrariar isso. Procuram adquirir alimentos em hortas particulares, que os vendem a preços mais baixos, e apostam na sopa, rica em legumes, como base fundamental da sua dieta e dos seus filhos. Todavia, constituem uma minoria.

O clima geral é de um abuso generalizado do sal e do açúcar que conduz a população portuguesa, no seu todo, a problemas sérios de saúde, como a diabetes e doenças de foro cardiovascular. O progressivo afastamento da Dieta Mediterrânica dá-nos disso um sinal inequívoco de apreensão.

Segundo os dados da BAP (Balança Alimentar Portuguesa) (INE, 2014) em 2015/16, verificou-se que existe um elevado uso de carne, pão e um consumo deficiente de produtos hortícolas, fruta e leguminosas. Passou-se de uma sociedade de carência, predominante no Estado Novo, para uma sociedade de abundância, com os seus riscos e malefícios inerentes. Objetivamente, mais de metade da população portuguesa tem excesso de peso, o que é algo deveras preocupante. Segundo o IAN-AF (Inquérito Alimentar Nacional e de Atividade Física), cerca de $57 \%$ da população é obesa ${ }^{12}$.

Tem havido algumas medidas no sentido de mudar isso. Por exemplo, a criação do Programa Nacional para Promoção da Alimentação Saudável, da DGS (Direção-Geral da Saúde) tem tido iniciativas meritórias, como a reforma alimentar nas escolas, que teve resultados díspares, e as campanhas pelo valor de saúde e cultural da Dieta Mediterrânica. Em 2020, a Comissão Europeia deu a lume um importante 
documento, intitulado Estratégia do Prado ao Prato:para um sistema alimentar justo, saudável e respeitador do ambiente, no qual se compromete a aumentar em $25 \%$ a agricultura biológica, até 2030. Paralelamente, adotaram-se também as seguintes medidas:

Na década de 2000 é desenvolvido o Primeiro Plano de Ação para as políticas alimentares e nutricionais (WHO European Region 2000-2005), que expressa a necessidade do desenvolvimento de políticas de alimentação e nutrição voltadas para a promoção da saúde, contribuindo por um lado para a redução das doenças relacionadas com a alimentação e por outro para o desenvolvimento socioeconómico e a sustentabilidade ambiental, por meio de uma ação políticas de alimentação e nutrição. (...) De acordo com este plano, as políticas de alimentação e nutrição devem objetivar ações em três grandes áreas: garantia da hígio-sanidade dos alimentos (food safety); promoção de uma alimentação/nutrição conducentes à otimização do estado de saúde e, por fim, garantia de uma adequada disponibilidade alimentar, quer em quantidade quer em qualidade, estimulando as economias rurais. (Graça \& Gregório, 2012, p. 86)

Sabemos que uma grande parte das perigosas alterações climáticas se deve à emissão de gases com efeito estufa, provenientes da indústria alimentar de carne, pelo que uma mudança nos hábitos alimentares se afigura vital para a saúde planetária. Aliás, muitos portugueses adotaram já comportamentos afins com esta estratégia. O número de adeptos do vegetarianismo, veganismo ou flexivegetarianismo aumentou exponencialmente nas duas últimas décadas, e, como já assinalei, começa a haver, em certos setores sociais, um saudável regresso aos critérios do PAM (Padrão Alimentar Mediterrânico) da Dieta Mediterrânica. Aliás, em relação ao vegetarianismo, ele tem já uma tradição que remonta ao início do século XX:

Chegaram a Portugal os ecos da alimentação vegetariana que se difundia além fronteiras, sendo um importante representante deste movimento Jaime de Magalhães Lima, que em 1912 publicou O Vegetarismo e a Moralidade das Raças. Com referências a várias personalidades que ao longo da História defenderam e praticaram uma vida de abstinência alimentar (...) O médico Amílcar de Sousa foi outro dos pioneiros do vegetarianismo em Portugal, dirigindo a revista mensal O Vegetariano, publicada a partir de 1909, que abrangia tanto temas de saúde, como relacionados com aspectos sociais e morais. Foi também o primeiro presidente da Sociedade Vegetariana de Portugal, fundada no Porto, em 1911. Esta editou, em 1916, o primeiro livro de receitas vegetarianas português, denominado Culinária Vegetariana, Vegetalina e Menus Frugívoros, da autoria de Julieta Ribeiro. (Grenha, 2011, p. 69)

Contudo, e para finalizar este ponto, deve ser assinalado que ainda se está muito de longe de atingir os números desejados. Há um longo caminho a percorrer. 


\section{Súmula e conclusão}

Em suma, Portugal deixou de ser o país malnutrido do Estado Novo, no qual poucos tinham acesso a uma alimentação rica e variada e onde as medidas de higiene eram inexistentes, para passar a ser uma sociedade de abundância, com as grandes melhorias daí advindas, mas também com os malefícios comuns a um mundo globalizado. O afastamento da tradicional Dieta Mediterrânica e a generalização da fast food sinalizam o lado negativo dessa mudança. Mas, no resto, a evolução trouxe coisas muito positivas.

As décadas do Pós 25 de Abril, os anos 80 e 90, foram muito importantes nas mudanças das práticas alimentares. Os hipermercados generalizaram-se e criou-se uma verdadeira rede de eletricidade, o que facultou o acesso aos eletrodomésticos, como o frigorífico e, mais tarde, o micro-ondas.

No século XXI, este pendor de mutação contínua acentuou-se. Assistimos a um certo grau de masculinização do espaço culinário. Hoje já se vêm homens a cozinhar, bem como a figura do cozinheiro foi reabilitada. Com a explosão do setor turístico, a comida portuguesa é, cada vez mais, um ícone de projeção exterior. Os chefes portugueses, com créditos internacionais afirmados, dedicam-se à reconstrução dos pratos tradicionais portugueses, com base na memória e na história portuguesas. Por outro lado, duas tendências, com origem nas últimas décadas do século passado, acentuaram-se. Em primeiro lugar, cada vez mais, os portugueses tendem a alimentar-se fora de casa. Isto interliga-se com a digitalização da comida. Por exemplo, a Uber Eats está, hoje, instalada em praticamente todos os centros urbanos portugueses. Em segundo, os restaurantes de origem étnica, como os de comida chinesa e brasileira, expandiram-se.

Em função da globalização, da inserção de Portugal no espaço comum europeu muitas das preocupações atuais advêm dessa abertura ao mundo. As preocupações climáticas e ecológicas também fazem sentir os seus efeitos no país. A agricultura biológica cresceu e o número de vegetarianos é o maior de sempre. Contudo, há um enorme caminho a percorrer nesse aspeto. Em termos de comparação com a maioria dos países inseridos na União Europeia, não se deve esquecer que Portugal é um dos mais pobres e isso tem consequências evidentes muito visíveis na alimentação:

As comparações de Portugal com os restantes países da União Europeia revelam alguma consistência com outros indicadores demográficos, sanitários e educativos: assiste-se a uma aproximação, por parte de Portugal, dos padrões europeus, relativamente às estruturas sociais. As taxas de actividade masculina e feminina, gerais ou por grupos etários, são semelhantes, exibindo Portugal valores acima de certos países e abaixo de outros. $\mathrm{O}$ mesmo é válido para as taxas de emprego. (...) Finalmente, as remunerações dos 
assalariados: quaisquer que sejam os termos de comparação, Portugal ocupa sempre, destacado, o último lugar. Muito longe dos países mais ricos e das médias europeias; e ainda longe da Espanha e da Grécia. (Barreto, 2017, pp. 54-55)

Portanto, ontem como hoje, a alimentação sinaliza desigualdades sociais. É mais fácil para o comum dos portugueses pagar comida rápida do que consumir peixe ou produtos de origem biológica. Claro que também é uma questão de informação e educação, mas a questão económica, neste caso, não é despicienda. Mães pobres, mas escolarizadas, optam pela sopa, como base da alimentação dos seus filhos.

Como se deduz deste quadro geral, a alimentação tem uma carga cultural e social muito forte. As mudanças num país passam inevitavelmente por ela. Se se voltasse aos critérios do PAM, de uma forma generalizada, isso seria sinal de outro grande salto na sociedade portuguesa. Mas, para já, estamos longe de lá chegar.

\section{Agradecimentos}

Este trabalho foi realizado com o apoio de Bolsa de Doutoramento, concedida pela Universidade de Aveiro, com a referência BD/REITORIA/9316/2020.

\section{Notas}

Por decisão pessoal, o autor do texto escreve segundo o novo acordo ortográfico

\section{Referências}

Barreto, A. (2017). De Portugal Para A Europa. Relógio D’Água Editores.

Berger, P. L., \& Luckman, T. (2010). A Construção Social da Realidade: Um Tratado da Sociologia do Conhecimento ( $3^{\mathrm{a}}$ ed.) (E. de Carvalho, Trad.). Dinalivro. (Obra originalmente publicada em 1996)

Bourdieu, P. (2011). O Poder Simbólico (2a ed.) (F. Thomaz, Trad.). Edições 70. (Obra originalmente publicada em 1989)

Dias, D., \& Baptista, M. M. (2006). Identidades-Ficções. Universidade de Aveiro.

Didier, P., Nguyen-The, C., Martens, L., Foden, M., Dumitrascu L., Mihalache, O. A., Nicolau, A. I., Skuland, S. E., Truninger, M., Junqueira, L., \& Maitre, I. (2021). Washing hands and risk of cross-contamination during chicken preparation among domestic practitioners in five European countries. Food Control, Disponível online a 6 de março de 2021.

Graça, P. (2020). Como Comem os Portugueses: alimentação. Fundação Francisco Manuel dos Santos/PORDATA. 
Graça, P., \& Gregório, M. J. (2012). Evolução da Política Alimentar e de Nutrição em Portugal e suas Relações com o Contexto Internacional. Revista SPCNA, 18(3), 79-96.

Grenha, P. (2011). Transformações do Consumo Alimentar na Época Contemporânea (Dissertação de Mestrado). Universidade de Coimbra.

Guerra, P., \& Marques, K. (2018). Culturas Alimentares: Identidades, Trânsitos e Metamorfoses. O Público e o Privado, (32), 15-38.

Hatton, B. (2017). Os Portugueses (12 ${ }^{\mathrm{a}}$ ed.) (P. Vidal, Trad.). Clube do Autor. (Obra originalmente publicada em 2011)

INE, Instituto Nacional de Estatística (2014, 2 de abril). Padrão das disponibilidades alimentares altera-se privilegiando os hidratos de carbono e cortando nas proteínas. [Destaque: informação à comunicação social].

Martins, M. do C. A. (2009, 11 de dezembro). Globalização da Alimentação: Unidade ou Diversidade? Repositório Científico do Instituto Politécnico de Castelo Branco. Publicação eletrónica antecipada. https:/ / repositorio.ipcb.pt/handle/10400.11/82

Mascarelhas, M. P. (2012, junho). Sociabilidades em Volta da Mesa. VII Congresso Português de Sociologia, Porto, Portugal.

ttps:/ / associacaoportuguesasociologia.pt/vii_congresso/ ?area $=016 \& l g=p t$

Mattoso, J. (2008). A Identidade Nacional (4 $4^{\mathrm{a}}$ ed.). Gradiva/Fundação Mário Soares.

Mónica, M. F. (2020a). Os Pobres (2 ${ }^{\mathrm{a}}$ ed.). A Esfera dos Livros.

Mónica, M. F. (2020b). O Olhar do Outro: Estrangeiros em Portugal: do Século XVIII ao Século $X X$. Relógio d'Água.

Rosa, M. J. V., \& Chitas, P. (2010). Portugal: Os Números (2a ed.). Fundação Francisco Manuel dos Santos/Relógio d' Água Editores.

Silva, L. F. da, Viera, C., \& Soares, B. (2000, abril). Práticas e Lógicas Quotidianas da Alimentação. IV Congresso Português de Sociologia. Sociedade Portuguesa: Passados Recentes, Futuros Próximos, Coimbra, Portugal. https://aps.pt/pt/atas-iv-congresso/

Truninger, M. (2018). Hábitos Alimentares dos Portugueses. Fundação Francisco Manuel dos Santos.

Data de submissão: 31/01/2021 | Data de aceitação: 15/07/2021 